\title{
The Salmonella effector protein SpvC, a phosphothreonine lyase is functional in plant cells
}

\author{
Christina Neumann ${ }^{1 \neq}$, Malou Fraiture ${ }^{2 \neq}$, Casandra Hernàndez-Reyes ${ }^{1}$, Fidele N. Akum ${ }^{1}$, \\ Isabelle Virlogeux-Payant ${ }^{3,4}$, Ying Chen ${ }^{2 \dagger}$, Stephanie Pateyron ${ }^{5}$, Jean Colcombet ${ }^{5}$, Karl-Heinz Kogel ${ }^{1}$, \\ Heribert Hirt ${ }^{5}$, Frédéric Brunner ${ }^{2}$ and Adam Schikora ${ }^{1 *}$ \\ ${ }^{1}$ Research Center for BioSystems, Land Use and Nutrition, Institute for Phytopathology and Applied Zoology, Justus-Liebig University Giessen, Giessen, Germany \\ ${ }^{2}$ Department of Plant Biochemistry, Center for Plant Molecular Biology (ZMBP), Eberhard Karls University Tübingen, Tübingen, Germany \\ ${ }^{3}$ Institut National de la Recherche Agronomique, UMR1282 Infectiologie et Santé Publique, Nouzilly, France \\ ${ }^{4}$ Université François Rabelais de Tours, UMR1282 Infectiologie et Santé Publique, Tours, France \\ ${ }^{5}$ Unité de Recherche en Génomique Végétale, Plant Genomics, Evry, France
}

Edited by:

Nicola Holden, The James Hutton Institute, UK

\section{Reviewed by:}

Frederik Börnke, Leibniz-Institute for Vegetable and Ornamental Crops (IGZ), Germany

Jeri Barak, University of

Wisconsin-Madison, USA

*Correspondence:

Adam Schikora, Research Center for BioSystems, Land Use and

Nutrition, Institute for

Phytopathology and Applied

Zoology, Justus-Liebig University

Giessen, Heinrich-Buff-Ring 26-32,

Giessen 35392, Germany

e-mail: adam.schikora@

agrar.uni-giessen.de

${ }^{\dagger}$ Present address:

Ying Chen, Laboratory of Forest Genetics and Gene Engineering,

Nanjing Forestry University, Nanjing,

China

${ }^{\ddagger}$ These authors have contributed

equally to this work.
Salmonella is one of the most prominent causes of food poisoning and growing evidence indicates that contaminated fruits and vegetables are an increasing concern for human health. Successful infection demands the suppression of the host immune system, which is often achieved via injection of bacterial effector proteins into host cells. In this report we present the function of Salmonella effector protein in plant cell, supporting the new concept of trans-kingdom competence of this bacterium. We screened a range of Salmonella Typhimurium effector proteins for interference with plant immunity. Among these, the phosphothreonine lyase SpvC attenuated the induction of immunity-related genes when present in plant cells. Using in vitro and in vivo systems we show that this effector protein interacts with and dephosphorylates activated Arabidopsis Mitogen-activated Protein Kinase 6 (MPK6), thereby inhibiting defense signaling. Moreover, the requirement of Salmonella SpvC was shown by the decreased proliferation of the $\triangle s p v C$ mutant in Arabidopsis plants. These results suggest that some Salmonella effector proteins could have a conserved function during proliferation in different hosts. The fact that Salmonella and other Enterobacteriaceae use plants as hosts strongly suggests that plants represent a much larger reservoir for animal pathogens than so far estimated.

Keywords: T3SS, trans-kingdom pathogenicity, Salmonella, plant infection

\section{INTRODUCTION}

Various pathogenic bacteria such as Salmonella enterica, Pseudomonas aeruginosa, Staphylococcus aureus, Escherichia coli O157:H7, and Listeria monocytogenes are able to proliferate on both animal and plant organisms (Prithiviraj et al., 2005; Milillo et al., 2008; Schikora et al., 2008, 2011; Haapalainen et al., 2009; Holden et al., 2009). Salmonella is a genus of Gram-negative enteropathogenic bacteria that colonizes a wide range of hosts, including humans. These bacteria are the causal agents of gastroenteritis and typhoid fever (Pang et al., 1995). The most common mode of infection in humans is the ingestion of contaminated food or water. Whereas $0.3 \%$ of fresh products were contaminated with Salmonella bacteria in 2007 in the European Union (Westrell et al., 2009), the proportion of raw-food related outbreaks reached $25 \%$ in the USA in recent years (Rangel et al., 2005).

The study of the Salmonella infection mechanism was until recently mainly driven by its medical aspect; therefore the mouse and human epithelial cell models are the best studied to date. Today, it is still poorly understood how these bacteria successfully proliferate in such diversified hosts as animals or plants. However, important insights were obtained during last years. Stomata openings were identified as possible entry points of bacteria into the inner layers of the mesophyll (Kroupitski et al., 2009). Interestingly, while some plant species (e.g., arugula) allow the Salmonella enterica subsp. enterica ser. Typhimurium (S. Typhimurium) strain SL1344 to internalize, some others (e.g., parsley) seem to be capable of preventing internalization (Golberg et al., 2011). In a previous report, we showed that in Arabidopsis thaliana, roots and especially root hair cells can be colonized by Salmonella (Schikora et al., 2008).

Studies of the infection mechanisms in animals revealed that, besides remodeling the host cell architecture, Salmonella actively suppresses the host immune system by injecting a cocktail of effector proteins. These effectors are delivered by Type III Secretion Systems (T3SSs). S. Typhimurium possesses two 
distinct T3SSs, T3SS-1, and T3SS-2, encoded by two Salmonella Pathogenicity Islands, SPI-1 and SPI-2, respectively. To date, about 44 Salmonella effectors have been described and the function of many of them is known [reviewed in Heffron et al. (2011)]. In addition to SPIs, some Salmonella serovars carry plasmids with a common locus called salmonella plasmid virulence $(s p v)$ (Boyd and Hartl, 1998). The spv operon encodes further effector proteins responsible for full virulence in humans and in the mouse model (Montenegro et al., 1991; Fierer et al., 1992; Gulig and Doyle, 1993; Chu and Chiu, 2006).

Even though some Salmonella effectors have homologs in plant pathogenic bacteria, the role of Salmonella T3SS-dependent effectors in the modulation of the plant immune system and their contribution to plant host susceptibility are less understood. Plants induce defense mechanisms after recognition of pathogens. This recognition may occur at two levels: (i) at the cell surface, where Pattern Recognition Receptors (PRRs) recognize conserved microbial structures called Pathogen-Associated Molecular Patterns (PAMPs), and (ii) in the cytoplasm where Resistance ( $\mathrm{R}$ ) proteins recognize bacterial effectors injected into plant cells. Both recognition events initiate immune responses referred to as Pattern-Triggered Immunity (PTI) [renamed from PAMP-triggered immunity (Boller, 2012)] or Effector-Triggered Immunity (ETI), respectively. An activation of MAPKs and enhanced expression of Pathogenesis Related $(P R)$ genes are hallmarks of both: the PTI and the ETI responses. Both responses were already observed after inoculation with Salmonella (Schikora et al., 2008; Meng et al., 2013; Garcia et al., 2014). Recently, the suppression of plant defense by Salmonella was reported in two different systems. In contrast to living $S$. Typhimurium, treatment with dead or chloramphenicol-treated bacterial cells elicited an oxidative burst and changes in apoplastic $\mathrm{pH}$ in tobacco (Shirron and Yaron, 2011). Similar responses were provoked by inoculation with the invA mutant, which has no functional T3SS-1, showing that T3SS-deficient or dead bacteria induce defense reactions while living wild-type bacteria actively suppress their induction. We observed a very similar phenomenon in Arabidopsis plants (Schikora et al., 2011). Inoculation with wild-type $S$. Typhimurium strain 14028s provoked changes in expression of 249 and 1318 genes at 2 and $24 \mathrm{~h}$ after infection, respectively (Schikora et al., 2011). However, inoculation with the $\operatorname{prgH}$ mutant, which has no functional T3SS-1, changed the expression of over 1600 genes at $24 \mathrm{~h}$. Gene ontology (GO) term enrichment analysis of the 649 prgH-specific genes revealed an overrepresentation of genes related to pathogen responses and ubiquitin-mediated protein degradation (Schikora et al., 2011; Garcia et al., 2014). Interestingly, this set includes $B A K 1, B I K 1$, WRKY18, WRKY33, EIN3, PR4, FRK1, 4CL, Sec61, and PUB23, all of which are up-regulated upon inoculation with pathogen or PAMP treatment. The higher expression levels of these genes after inoculation with the $\mathrm{prgH}$ mutant compared to the wild-type imply that the mutant is lacking an effective suppression mechanism to hinder plant defense. A powerful response to pathogen attack is the hypersensitive response (HR). This induced cell death is often the reaction to bacterial proteins present in the host cytoplasm (Jones and Dangl, 2006). In respect to Salmonella effector proteins, SseF was the first effector reported to induce HR-like symptoms in tobacco plants (Ustun et al., 2012). The fact that SseF-induced HR-like symptoms can be suppressed by RNAimediated silencing of SGT1 (Suppressor of G2 allele of Skip1) indicates an R-protein-mediated response, identical to ETI.

In this report, we present two functional screens of Salmonella effector proteins and virulence factors in plants. Our screens resulted in the identification of the phosphothreonine lyase SpvC, which was able to suppress PTI. Using in vitro and in vivo systems we showed that this effector protein actively interacts with and dephosphorylates activated Arabidopsis Mitogen-activated Protein Kinase 6 (MPK6). MAPKs are important regulators of the immune response in animals and plants and the dephosphorylation of MPK6 hinders the induction of defense-related genes in Arabidopsis. Moreover, we showed that bacterial fitness on Arabidopsis plants is compromised in mutants lacking the SpvC gene. These results strengthen the notion that some Salmonella effectors may be equally applied in plant and animal systems to suppress the respective host immune systems.

\section{MATERIALS AND METHODS PLANT GROWTH CONDITIONS}

Arabidopsis thaliana Colombia-0 (N60000) plants were cultivated on soil under stable climate conditions: $8 \mathrm{~h}$ light/16 h dark at $20^{\circ} \mathrm{C}, 40-60 \%$ humidity, $\sim 120 \mu \mathrm{E} \mathrm{m}-2$ s-1 light intensity. Leaves from 4 -week old plants were used for protoplast preparation and analysis of transient gene expression. Alternatively Arabidopsis seedlings were germinated on sterile half-strength MS agar medium and cultivated for 2 weeks in short-day conditions (at $21^{\circ} \mathrm{C}, 60 \%$ humidity) in growing chambers. Nicotiana benthamiana plants were germinated and cultivated on soil, in a greenhouse under long-day conditions $\left(16 \mathrm{~h}\right.$ light at $22^{\circ} \mathrm{C}$, $40-60 \%$ humidity) for 4 weeks.

\section{CLONING OF SALMONELLA VIRULENCE FACTORS AND SPI-DEPENDENT EFFECTOR PROTEINS}

Fifty-four Salmonella virulence genes, which when mutated caused the attenuation of virulence in the mouse model, and genes coding 18 SPI-1- or SPI-2-encoded effectors from Salmonella enterica subsp. enterica serovar Typhimurium strain 14028s (S. Typhimurium) were cloned into the versatile Gateway (Invitrogen) vector system. All open reading frames (ORFs) were constructed in two versions: one including the native stop codon: the STOP version and a second without the stop codon: the END version. Cloning was based on the ATOME cloning strategy (http://urgv.evry.inra.fr/ATOMEdb). The consequential entry clones were sequenced and those with correct ORFs were used for further studies. For the screen in Arabidopsis protoplasts, the ORFs were further recombined into p2GW7 (VIB, University of Ghent). $S p v C$ was additionally cloned into p2FGW7 (VIB, University of Ghent) for expression of the N-terminal GFP fusion protein GFP-SpvC.

\section{BACTERIAL MUTAGENESIS}

The $S p v C$ mutant $\Delta s p v C$ of the $S$. Typhimurium 14028 strain was obtained using the $\lambda$-Red mutagenesis system as described by Datsenko and Wanner (2000). The sequences of the primers used were: 5'ATGCCCATAAATAGGCC 
TAATCTAAATCTAAACATCCCTCCTTTGAATATGTGTAGGCT GGAGCTGCTTC $3^{\prime}$ and 5'TTACTCTGTCATCAAACGATAAAAC GGTTCCTCACGTAAAGCCTGTCTCTCATATGAATATCCTCCT TAG3'.

\section{AGROBACTERIUM-MEDIATED TRANSFORMATION}

The Gateway compatible pGreen derivative vectors pJC005 and pJC001 for expression of 10xMyc- or 3xHA-tagged recombinant proteins, respectively, carrying Salmonella ORFs, were transformed into the Agrobacterium tumefaciens strain GV3101, pMP90. Transformed bacteria were cultivated until stationary phase, washed in infiltration medium $\left(10 \mathrm{mM} \mathrm{MgCl}_{2}, 10 \mathrm{mM}\right.$ MES-KOH, pH 5, 4, $200 \mu \mathrm{M}$ acetosyringone) and incubated for $2 \mathrm{~h}$ in the dark. $\mathrm{OD}_{600}$ of the infiltration solution was then adjusted to 0.3 . Leaves of $N$. benthamiana were infiltrated one-sided.

\section{PROTOPLAST TRANSFORMATION}

The preparation of Arabidopsis mesophyll protoplasts was performed according to the protocol from Yoo et al. (2007) with minor changes (Fraiture et al., 2014). Briefly, thin leaf stripes were dipped into $1.5 \%$ cellulose "Onozuka" R10-0.4\% macerozyme R10 solution (Yakult Pharmaceutical Industry), vacuum-infiltrated for $30 \mathrm{~min}$ and digested for $3 \mathrm{~h}$ at $20^{\circ} \mathrm{C}$ in the dark. After two subsequent washing steps with W5 buffer Arabidopsis protoplasts were suspended to a concentration of $2 \times 10^{5}$ cells/ml in MMG buffer and subjected to polyethylene glycol-mediated transfection. $100 \mu \mathrm{g}$ plasmid DNA/ml protoplast suspension was used during transfection. Protoplasts samples were then incubated in $\mathrm{W} 1$ buffer at $20^{\circ} \mathrm{C}$ in the dark for $12-16 \mathrm{~h}$ allowing plasmid gene expression.

\section{LUCIFERASE REPORTER GENE ASSAYS}

Luciferase gene assays were conducted to screen for immunitysuppressing effects of effector proteins from Salmonella (Fraiture et al., 2014). For this, Arabidopsis protoplasts were co-transfected with pFRK1-Luciferase ( $p$ FRK1-Luc) and a candidate effector gene in p2GW7 (or empty p2FGW7 serving as GFP control). For the assay, luciferin was added to $600 \mu \mathrm{l}$ transfected protoplast solution to a final concentration of $200 \mu \mathrm{M}$. Protoplasts were transferred to an opaque 96 -well plate $(100 \mu l$ per well). For each sample, flg22 was added to 3 wells to a final concentration of $500 \mathrm{nM}$. The remaining 3 replicates were left untreated. The luminescence reflecting the luciferase activity was measured at different time-points using a Berthold Mithras LB 940 luminometer.

\section{RNA ISOLATION AND QUANTITATIVE REAL-TIME PCR}

Total RNA from $400 \mu$ l protoplast solution was extracted with TRI reagent (Ambion) and treated with DNase I (MachereyNagel) following the suppliers' protocols. Poly A-tailed RNA $(1 \mu \mathrm{g})$ was converted to cDNA using the RevertAid reverse transcriptase (Fermentas) and oligo-dT primers. qRT-PCR reactions were performed in triplicates with the Maxtra SYBR Green Master Mix (Fermentas) and run on a Biorad iCycler according to the manufacturer's instructions. The primers used for the qRT-PCR are presented in Supplementary Table S1. Relative gene expression was determined with a serial cDNA dilution standard curve.
The actin transcript was used as an internal control in all experiments. Data was processed with the iQ software (Biorad) (Zheng et al., 2014).

\section{IMMUNOBLOT ANALYSIS}

To monitor the activation of MAPKs, Salmonella effector-gene transformed protoplasts were challenged with $500 \mathrm{nM}$ flg22 (Zheng et al., 2014). Pellets from $100 \mu \mathrm{l}$ protoplast solution were collected 0,15 , and $30 \mathrm{~min}$ after treatment and dissolved in denaturating protein loading buffer. Proteins were separated by SDS-PAGE, blotted onto nitrocellulose membranes (HybondECL, Amersham) and stained with $0.1 \%$ Ponceau $S$ to visualize equal sample loading. The membranes were incubated with antiphospho-p44/42 MAPK antibody (Cell Signaling Technology) diluted $1 / 1000$ in 5\% BSA TBS-T. The expression of GFPtagged Salmonella virulence proteins and effectors was assessed in Arabidopsis protoplasts collected $24 \mathrm{~h}$ after transformation using an anti-GFP antibody. The immunoblot was revealed in NBT/BCIP detection solution.

\section{PROTEIN PURIFICATION}

Recombinant GST-SpvC and 6xHis-SpvC proteins were produced in E. coli BL21 bacteria using the pDEST15 and PDEST17 vectors (Invitrogen). Protein expression was induced with $1 \mathrm{mM}$ IPTG overnight at $30^{\circ} \mathrm{C}$. Cells were lysed and protein purified accordingly to the manufacturers' protocols (Macherey-Nagel for GTH-beads and Qiagen for Ni-beads purifications).

\section{PULL-DOWN ASSAY}

For the pull-down assay $50 \mu \mathrm{g}$ of purified recombinant proteins were incubated with $50 \mu \mathrm{g}$ of total Arabidopsis protein extract in the presence (or absence) of $80 \mu \mathrm{g}$ BSA for $30 \mathrm{~min}$ in a final volume of $200 \mu \mathrm{l}$ at $21^{\circ} \mathrm{C}$ together with the corresponding beads. Beads were washed 3 times and Ni- or GTH- binding complexes separated by SDS-PAGE. Anti-MPK6, anti-MPK3, or anti-MPK4 antibodies (Sigma-Aldrich) were used to visualize the binding between SpvC and MAPKs.

\section{BiFC}

Bimolecular fluorescence complementation (BiFC) assay was performed using the full-length versions of MAPKs and $S p v C$ cloned down-stream of N-terminal or C-terminal part of gene coding for the Yellow Fluorescent Protein (YFP) in both combinations, using pBIFC1-4 vectors. Arabidopsis epidermal cells were cotransformed with vectors carrying those constructs and vector carrying $p 35 S-m C h e r r y$. Fluorescence was observed $24-48 \mathrm{~h}$ after transformation. Expression of $m$ Cherry was used as readout for successful transformation. Reconstitution of functional YFP was observed with the $510-540 \mathrm{~nm}$ band pass filter on a Leica SP2 confocal laser-scanning microscope.

\section{IN VITRO DEPHOSPHORYLATION ASSAY}

The phosphatase activity of SpvC on activated MAPKs was assessed using $25 \mu \mathrm{g}$ purified recombinant GST-SpvC or 6xHisSpvC proteins and $50 \mu \mathrm{g}$ of total protein extract from Arabidopsis seedlings treated or not (control) with $1 \mu \mathrm{M}$ flg22 for $15 \mathrm{~min}$. Recombinant effector proteins and Arabidopsis proteins were coincubated for $30 \mathrm{~min}$ at $21^{\circ} \mathrm{C}$. Samples were precipitated using 
a chloroform/methanol procedure and separated by SDS-PAGE. The presence of the phosphorylated pTEpY epitope was probed with anti-pERK1/2 antibody (see above).

\section{PATHOGENICITY ASSAY}

To assess the Salmonella proliferation rate in plants, soil-grown, 4-week old Arabidopsis Col-0 plants were infiltrated with wildtype Salmonella enterica subsp. enterica ser. Typhimurium strain $14028 \mathrm{~s}$ or its isogenic mutant $\Delta s p v C$, using syringe infiltration. Bacteria were grown in LB medium until early log phase, washed and re-suspended in $10 \mathrm{mM} \mathrm{MgCl}_{2}$. Infiltration solution was adjusted to $\mathrm{OD}_{600}=0.01\left(1.7 \times 10^{6}\right.$ bacteria/ml $)$. Bacterial population was monitored during 4 days post-infiltration as described in Schikora et al. (2008).

\section{INCOMPATIBLE INTERACTION}

To test the breach of non-host resistance, leaves from soil-grown Arabidopsis plants were transformed with $p 35 S-G F P-S p v C$ or $m$ Cherry via particle bombardment and inoculated with Blumeria graminis f. sp. hordei (Bgh) conidia. After $48 \mathrm{~h}$, leaves were stained with calcofluor to visualize fungal growth. The outcome of interaction was counted on cells transformed either with mCherry (control) or plasmid carrying GFP-SpvC.

\section{RESULTS}

\section{A DUAL SCREEN FOR SALMONELLA VIRULENCE FACTORS AND EFFECTOR PROTEINS ACTIVE IN PLANT CELLS}

To identify the important factors for Salmonella pathogenicity on plants we decided to follow a two-screening-strategy through a set of Salmonella virulence factors (SVFs) and Salmonella Pathogenicity Islands (SPIs)-encoded effector proteins. We chose 54 SVF genes, which when mutated caused an attenuation of virulence in the mouse model (PHI-base, www.phi-base.org), and 18 SPI-1- or SPI-2-encoded effectors (Heffron et al., 2011) from Salmonella enterica subsp. enterica ser. Typhimurium strain 14028s (S. Typhimurium) for cloning into the versatile Gateway (Invitrogen) vector system. Cloned genes resulted in a set of Salmonella ORFs used for further studies. In a first step, 37 ORFs were successfully cloned into binary vectors for Agrobacteriummediated expression in tobacco (Nicotiana benthamiana) leaves. Salmonella SVFs and effectors were expressed as N-terminal $10 \mathrm{xMyc}$ or $3 \mathrm{xHA}$ fusion proteins and symptoms caused by the expression were observed during 5 days after infiltration. We identified eight proteins (SseF, OrgA, Orf4, SsaI, SsaQ, HilC, SicA, and SseG), which caused chlorosis, wilting or hypertrophy on tobacco leaves (Figure 1), while the expression of the others, provoked no visible symptoms (Table $\mathbf{1}$ ).

Next, we tested the potential of the proteins inducing visible changes in tobacco leaves for suppressing early defense responses. Additionally, we tested 5 selected Salmonella effectors (AvrA, SptP, SlrP, SseL, SpvC) for which the biochemical function and/or suppression of immunity in mammals has well been characterized (Heffron et al., 2011). We used a protoplast-based system in Arabidopsis in which transiently expressed effectors were evaluated for their capability to suppress PAMP-triggered activation of luciferase (Luc) activity. In our screen Luc expression was driven by the FRK1 promoter, which is strongly induced upon treatment with the PAMP flg22, a 22 amino acid long peptide derived from the N-terminal part of flagellin and conserved in many pathogenic bacteria including Pseudomonas aeruginosa, Escherichia coli and S. Typhimurium (Felix et al., 1999). Out of the 13 tested Salmonella proteins, a strong suppression of pFRK1-Luc activity $6 \mathrm{~h}$ after flg 22 treatment was observed when co-expressing the SpvC effector protein $(p<0.01$, oneway ANOVA and Dunnett's test) compared to the GFP control (Figure 2A and Supplementary Figure S1). The suppression effect was comparable $(p>0.05)$ with AvrPto from Pseudomonas syringe, an effector that is known to interfere with early PAMP signaling (He et al., 2006). In addition, significant suppression $(p<0.01)$ was observed when expressing SseL, SseG, and SseF (Figure 2A). In order to confirm our observations we performed a time-course experiment, in which we analyzed $p F R K 1-L u c$ activity in $S p v C$-transformed protoplasts during $8 \mathrm{~h}$ after induction with flg22 (Figure 2B). SpvC and AvrPto have similar effects on the activity of $p F R K 1$ suggesting that SpvC may, similarly to AvrPto, affect PAMP signaling at an early stage ( $4 \mathrm{~h}$ or earlier). Comparable observations were made when the fusion protein Green Fluorescent Protein-SpvC (GFP-SpvC) protein was expressed (Figure 2A). The localization analysis performed with GFP-SpvC fusion protein indicated that the effector protein localizes to the cytoplasm and nucleus when present in plant cells (Figure 2C). In the following experiments we decided to focus on SpvC, because of its well-known inhibitory effect on immunity during animal infection (Mazurkiewicz et al., 2008).

\section{SALMONELLA SpvC EFFECTOR SUPPRESSES THE EXPRESSION OF PAMP-INDUCED GENES}

In a next step, we analyzed the effect of SpvC on the activity of the endogenous FRK1 promoter. To this end, we measured the expression of FRK1 in Arabidopsis protoplasts transformed with $S p v C, A v r P t o$, or GFP after 1 and $3 \mathrm{~h}$ challenge with flg22. Equally to previous experiments and in accordance with the literature (Asai et al., 2002), expression of FRK1 was induced upon treatment with flg22. Expression of AvrPto efficiently suppressed this induction in Arabidopsis protoplasts (He et al., 2006). Likewise, SpvC also abolished the induction of endogenous FRK1 expression after flg22 treatment (Figure 3). We extended our analysis to other PAMP-induced genes. Similar to FRK1, the transcription factor WRKY17 and the gene encoding for the protein transport protein Sec61 were induced upon flg22 treatment and hindered in their inductions by AvrPto and SpvC (Figure 3). Remarkably, SpvC did not suppress all tested PAMP-induced genes. The $4 C L$ gene encoding a 4-coumarate-CoA ligase was induced after flg22 treatment and repressed in the presence of AvrPto. However, in contrast to AvrPto, SpvC was not able to restrain its flg22-driven induction (Figure 3). These results suggest that the Salmonella effector SpvC interferes only with a subset of flg22-induced defense related genes (FRK1, WRKY17, and Sec61, but not 4CL).

\section{INTERACTION BETWEEN ARABIDOPSIS MPK6 AND SALMONELLA SpvC}

Inhibition of flg22-induced gene expression by bacterial effectors can occur at many levels from the flg22 receptor complex 


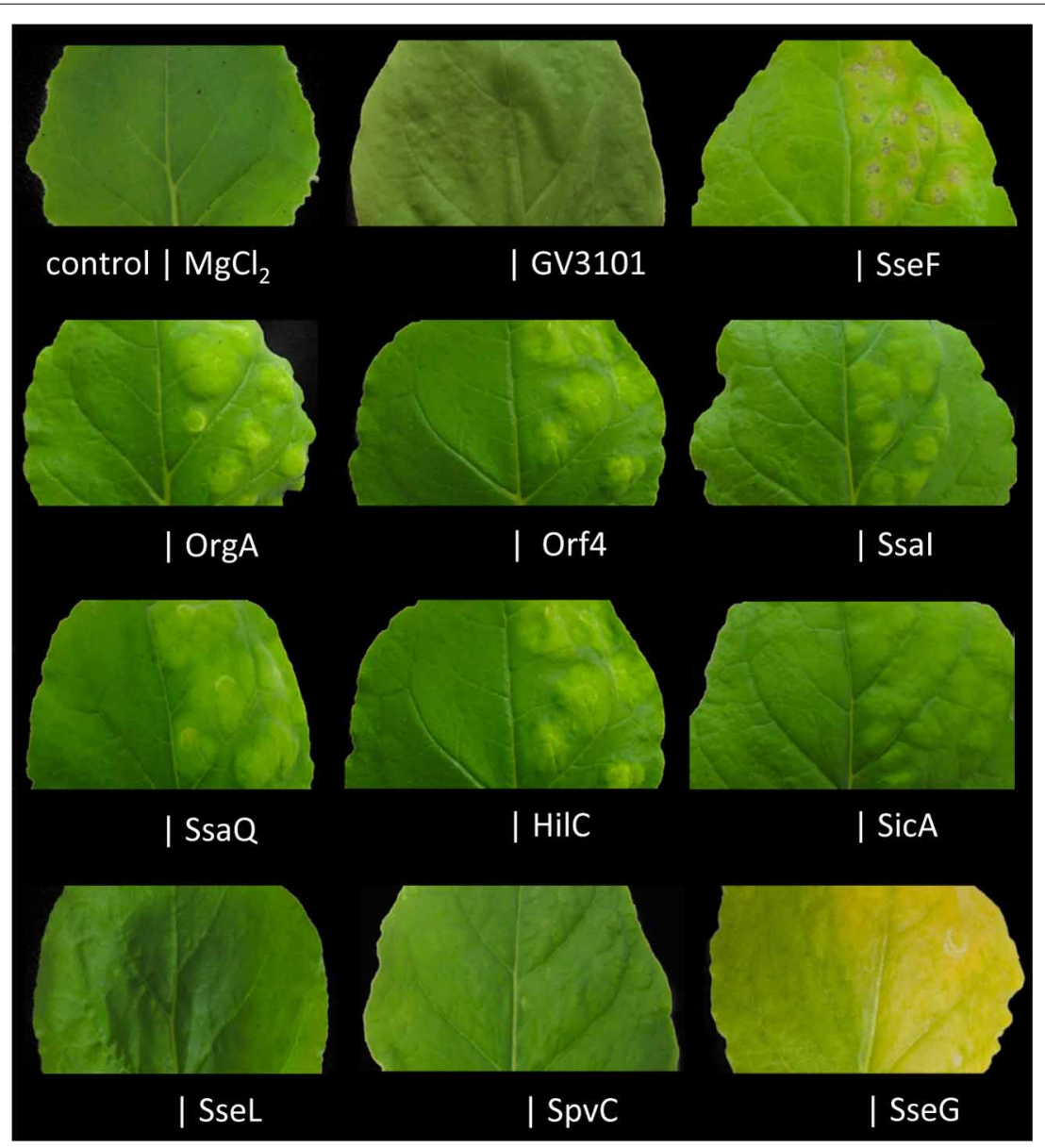

FIGURE 1 | Screen for Salmonella proteins that induce HR-like symptoms in plants. SVF and effector genes were cloned into plant expression vectors and expressed as $\mathrm{HA}$ - and Myc-tagged versions in $\mathrm{N}$. benthamiana leaves via Agrobacterium-mediated transformation. Symptoms were observed 5 days after infiltration. Expression of eight proteins resulted in macroscopic changes in leaf morphology when compared to the non-transformed parts of the leaf (control), transformation with Agrobacterium GV3101 or infiltration with $10 \mathrm{mM} \mathrm{MgCl}_{2}$. The experiment was repeated 4 times with both versions of bacterial fusion protein. Only the right side of the leaf was infiltrated.
(FLS2-BAK1), through the MAPK cascade, down to transcriptional regulation of defense genes. MAPK cascades play a key role in flg22 signal transduction and in pathogen defense. Among the 20 Arabidopsis MAPKs, MPK3, MPK4, and MPK6 are strongly activated by flg22 (Asai et al., 2002; Pitzschke et al., 2009). Based on the functional characteristics of SpvC during animal infection as well as the function of other members of the OspF family [e.g., HopAI1 (Zhang et al., 2007)], we hypothesized that SpvC targets plant MAPKs. To test our hypothesis, we analyzed possible protein-protein interactions between SpvC and Arabidopsis MAPKs. Recombinant 6xHis-SpvC and GST-SpvC proteins were expressed and purified from E. coli BL21 cells. The recombinant proteins were subsequently co-incubated with total protein extract from Arabidopsis seedlings and either Ni- or GTH-coated beads were used to precipitate the respective Ni- or GTH-binding complexes. Pull-down samples were probed for the presence of MAPKs in immunoblot assays. In the presence of His-tagged, but not GST-tagged SpvC, we detected the MPK6 in the pulleddown protein complex (Figure 4A), suggesting the interaction between SpvC and MPK6. This interaction was observed even in the presence of an excess of BSA. However, we did not detect MPK3 or MPK4, indicating a specific interaction between SpvC and MPK6.

The in vitro SpvC-MPK6 interaction was tested also in bimolecular fluorescent complementation (BiFC) assays. Fulllength cDNAs of $S p v C$ and the three MAPKs were cloned downstream of sequences encoding either the N- or C-terminal part of the Yellow Fluorescent Protein (YFP) and subsequently transiently expressed in Arabidopsis epidermal cells via particle bombardment. Both tested combinations: (i) YFPn-MPK6 with YFPc-SpvC and (ii) YFPn-SpvC with YFPc-MPK6, when expressed together, resulted in reconstitution of a functional YFP protein (Figure 4B). We co-expressed the constructs with p35S-mCherry plasmid, allowing normalization of the interaction events (Figure 4C). Eighteen percent of all transformed cells showed visible interaction between SpvC and MPK6 when $Y F P n-M P K 6$ was co-expressed with YFPc-SpvC, and $34 \%$ of all cells when $Y F P n-S p v C$, and $Y F P c-M P K 6$ were used as interaction 
Table 1 | Salmonella ORFs cloned for screens in plants.

\begin{tabular}{|c|c|c|c|}
\hline \multirow[t]{2}{*}{ Gene } & \multicolumn{2}{|c|}{ Tobacco assay } & \multirow[t]{2}{*}{ Protoplast assay } \\
\hline & 10xMyc & $3 \times \mathrm{HA}$ & \\
\hline
\end{tabular}

\begin{tabular}{|c|c|c|c|}
\hline \multicolumn{4}{|c|}{ Salmonella VIRULENCE FACTORS } \\
\hline$s s r B$ & - & - & \\
\hline$s s a B$ & - & - & \\
\hline sse $E$ & - & - & \\
\hline sseF & $\mathrm{HR}$ & $\mathrm{HR}$ & PTI suppression \\
\hline sifA & - & - & \\
\hline $\operatorname{sir} A$ & - & - & \\
\hline $\operatorname{org} A$ & Hypertrophy & Hypertrophy & - \\
\hline orf2 & - & - & \\
\hline $\operatorname{ttr} B$ & - & - & \\
\hline ssaM & - & - & \\
\hline orf2 & - & - & \\
\hline orf4 & Hypertrophy & Hypertrophy & - \\
\hline$s s a E$ & - & - & \\
\hline$s s e D$ & - & - & \\
\hline$s s c B$ & - & - & \\
\hline ssal & Hypertrophy & Hypertrophy & - \\
\hline ssaJ & - & - & \\
\hline ssak & - & - & \\
\hline ssaM & - & - & \\
\hline$s s a Q$ & Hypertrophy & Hypertrophy & - \\
\hline$y s c R$ & - & - & \\
\hline ssas & - & - & \\
\hline ssat & - & - & \\
\hline hilC & Hypertrophy & Hypertrophy & - \\
\hline $\operatorname{prgK}$ & - & - & \\
\hline prgJ & - & - & \\
\hline $\operatorname{iag} B$ & - & - & \\
\hline $\operatorname{sic} A$ & Hypertrophy & Hypertrophy & Weak PTI suppression \\
\hline invl & - & - & \\
\hline $\operatorname{inv} E$ & - & - & \\
\hline$s p v R$ & - & - & \\
\hline
\end{tabular}

Salmonella T3SS-1 AND T3SS-2 DEPENDENT EFFECTORS

$\begin{array}{lccc}\text { avrA } & - & - & - \\ \operatorname{sptP} & - & - & - \\ \text { slrP } & - & - & - \\ \text { sseL } & - & - & \text { PTI suppression } \\ \text { spvC } & - & - & \text { PTI suppression } \\ \text { sseG } & \text { Yellowing } & \text { Yellowing } & \text { PTI suppression }\end{array}$

Symptoms observed on tobacco leaves 5 days after infiltration with Agrobacterium tumefaciens (tobacco assay) or suppression of the pFRK1-Luc activity in protoplasts challenged with flg22 (protoplast assay). HR, hypersensitive response; -, represents no difference to controls.

partners. Arabidopsis MPK6 localizes to the cytoplasm and nucleus, but accumulates in the nuclear compartment after activation (Bethke et al., 2009). The observed cytoplasmic and nuclear localization of SpvC-MPK6 complex had similar localization. Moreover, this localization overlapped with the localization of the GFP-tagged versions of SpvC in epidermal cells (Figure 2C). Similarly to the in vitro assay, we did not observe an interaction between SpvC and the other MAPKs (MPK3 and MPK4) (Figure 4B). Hence, these results indicate that SpvC interacts with Arabidopsis MPK6.

\section{ACTIVATED MAPKs ARE DEPHOSPHORYLATED BY SpvC}

By monitoring in vitro the phosphorylation status of MAPKs after activation with flg22 in the presence of SpvC, we tested the assumption that SpvC might dephosphorylate the double phosphorylated active forms of MAPKs. The recombinant proteins 6xHis-SpvC and GST-SpvC were expressed in E. coli BL21 cells and purified with the respective affinity chromatography (Nisepharose or GTH-agarose columns, respectively). Arabidopsis MAPKs were activated by challenge of intact seedlings with flg22. Total proteins from those seedlings were incubated with recombinant SpvC protein (Figure 5A). The activation of the MAP kinases can be efficiently detected by means of an anti-pERK1/2 antibody that recognizes the phosphorylated $\mathrm{T}$ and $\mathrm{Y}$ residues in the activation loop (pTEpY) of MAPKs (Hamel et al., 2005). In Figure 5, the upper panel presents the phosphorylation status of MPK6 (upper band) and MPK3 (lower band) as detected by means of the anti-pERK1/2 antibody ( $\alpha$ EERK1/2). Twenty minutes after treatment of Arabidopsis seedlings with flg22, the detected signals indicated active, phosphorylated MAPKs. It should be noted that the $30 \mathrm{~min}$ incubation time, which is necessary to carry out this assay, did not affect the phosphorylation on the TEY epitope. When 6xHis-SpvC or GST-SpvC proteins were added to the Arabidopsis protein extract, the phosphorylated pTEpY epitope of the MAPK was no longer detectable (Figure 5A, $\alpha \mathrm{pERK} 1 / 2$ blot). This result suggests that $\mathrm{SpvC}$ is able to dephosphorylate activated plant MAPKs in vitro.

In the next step we sought to verify the result in an in vivo system. To achieve this aim, we expressed $S p v C$ as native or GFP-tagged protein in Arabidopsis protoplasts, and subsequently assessed the phosphorylation status of MAPKs after flg22 treatment. As controls we transformed the protoplasts with GFP or the effector AvrPto, which is known to inhibit MPK6 phosphorylation (He et al., 2006). In GFP-expressing protoplasts, flg22triggered transient activation of MAPKs was peaking after $15 \mathrm{~min}$ (Figure 5B). In contrast, protoplasts expressing AvrPto, SpvC as well as GFP-SpvC showed complete inhibition of MAPK activity (Figures 5B,C). These results are in line with the dephosphorylation activity of SpvC observed in vitro, as well as the suppressing effect on defense gene activation. Moreover, they support the idea that SpvC interferes with plant defense signaling upstream or at the level of the MAPKs.

\section{EXPRESSION OF SpvC BREACHES THE NON-HOST RESISTANCE IN ARABIDOPSIS}

MAPKs are key components of immune signaling in plants. Accordingly, we assumed that manipulation and inactivation of MAPKs by SpvC might affect plant resistance. To verify this, we analyzed the resistance of epidermal cells transformed with $S p v C$ toward the fungal pathogen Blumeria graminis f. sp. hordei (Bgh). Arabidopsis is a non-host for $B g h$ and copes easily with this fungus either by papillae formation or by hypersensitive response (HR) at the infection site. $S p v C$ was transiently expressed in Arabidopsis epidermal cells under the control of the constitutive $35 \mathrm{~S}$ promoter 


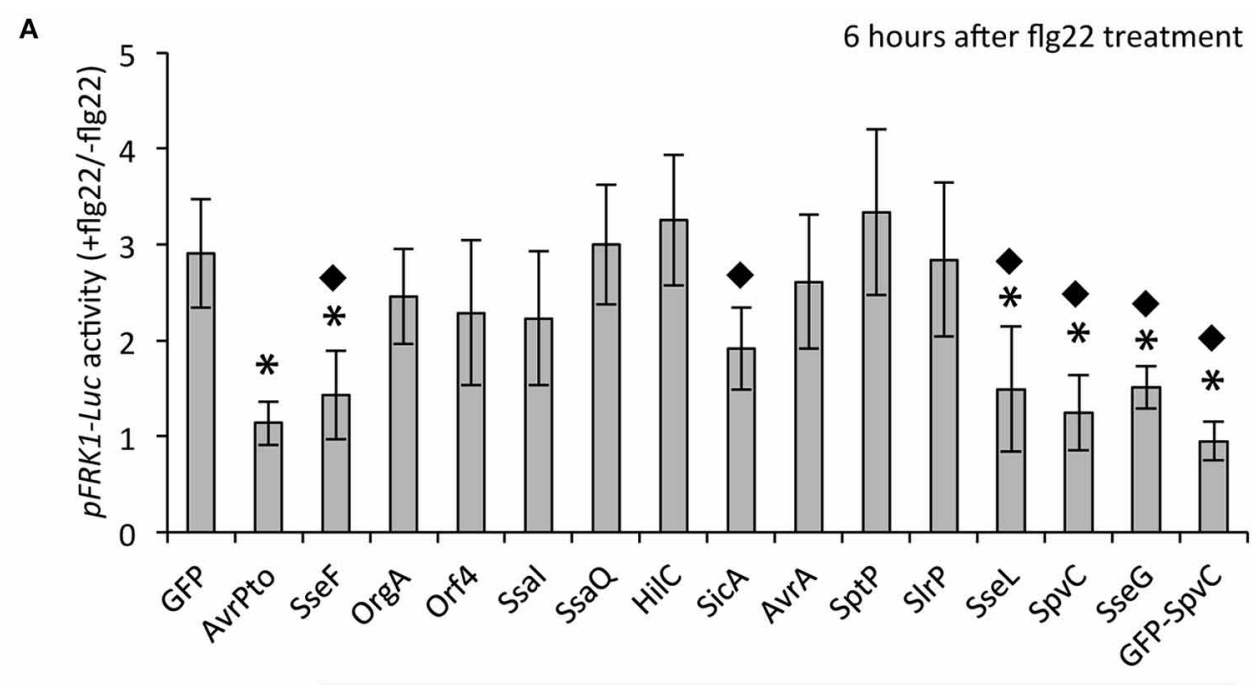

Salmonella virulence factors and effector proteins
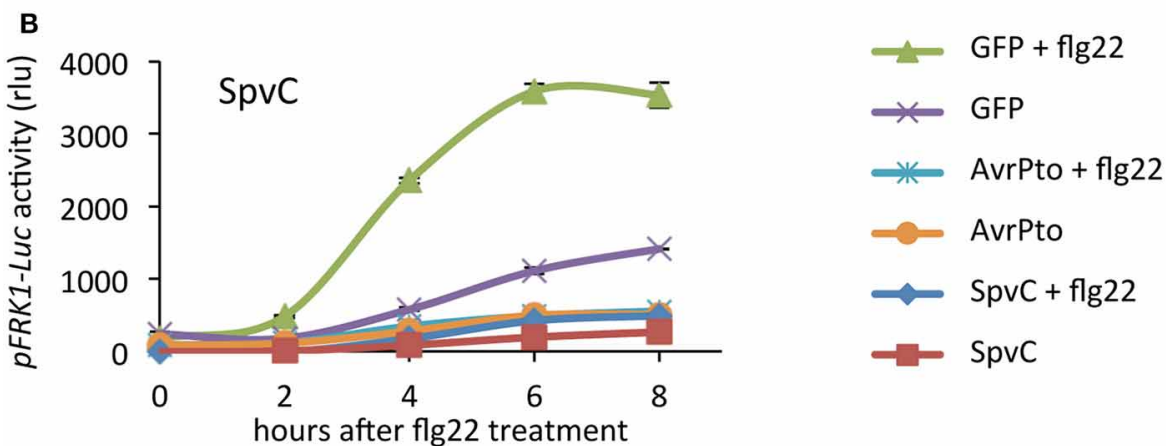

C

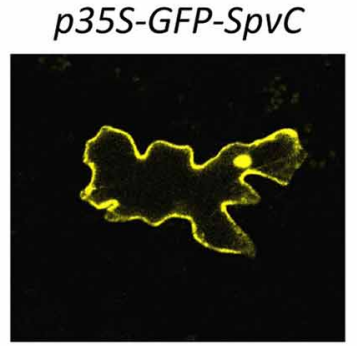

p35S-dsRED

overlay
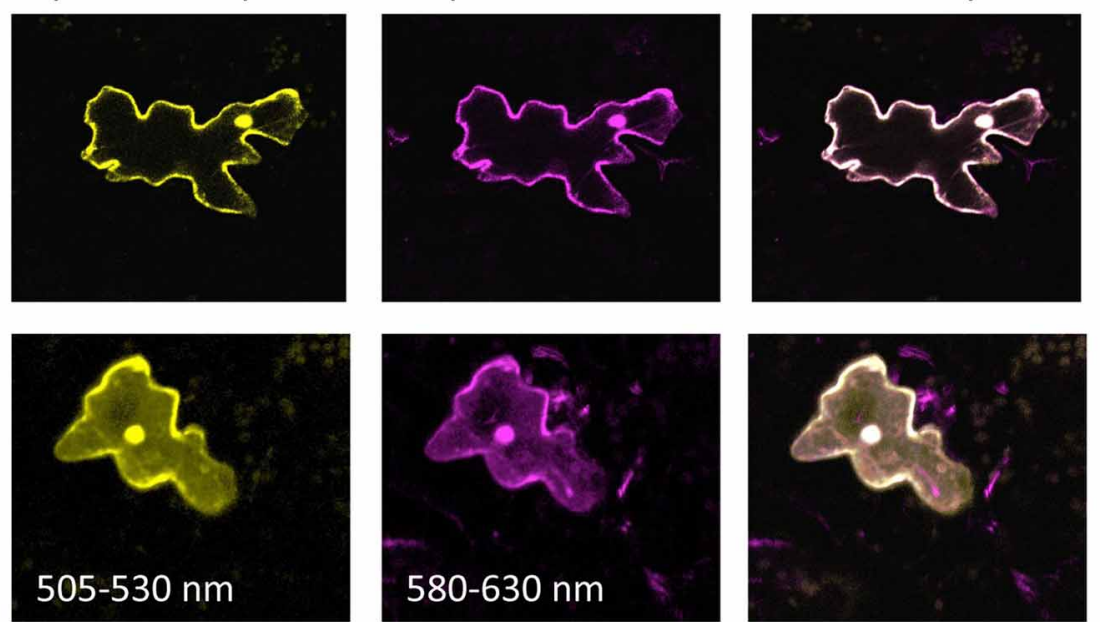

FIGURE 2 | Suppression of flg22-induced pFRK1-Luc expression by Salmonella proteins. (A) Mesophyll protoplasts from Arabidopsis thaliana Col-0 were co-transformed with pFRK1-Luc and p35S-Salmonella-ORF plasmids. Co-transformations of pFRK1-Luc with p2FGW7 (GFP) and with p2GW7-AvrPto (AvrPto) plasmids served as controls. Protoplasts were subsequently treated with flg22 or left untreated. The ability to suppress the flg22-driven activation of $p F R K 1-L u c$ of chosen virulence factors and effectors was assessed $6 \mathrm{~h}$ later by measuring luciferase (Luc) activity. Results are presented as ratio between flg22-treated and non-treated samples (+flg22/-flg22). For each effector, at least four independent experiments with three technical replicates were carried out. All data were pooled. Mean values \pm SD are plotted. One-way ANOVA followed by Dunnett's multiple comparison test was performed to assess significant differences between (Continued) 


\section{FIGURE 2 | Continued}

the GFP control and the virulence factor- and effector- protein-producing samples. An asterisk marks data sets with $p<0.01$. The same test was performed to assess the difference between Salmonella effectors and AvrPto. A diamond represents those proteins, which have similar effects to AvrPto at $p>0.05$. (B) Representative time-course experiment of flg22-mediated pFRK1-Luc activity in Arabidopsis protoplasts expressing
GFP, AvrPto or SpvC. Luciferase activity was measured every $2 \mathrm{~h}$ for $8 \mathrm{~h}$ after flg22 challenge. The data represents mean values \pm SD from three technical replicates. rlu; relative light units. (C) Localization study of a GFP-SpvC fusion protein produced under the $35 \mathrm{~S}$ promoter in Arabidopsis leaves transformed via particle bombardment. Cytoplasmic and nuclear localized dsRED protein was used as a control. Images present two exemplary cells (lower and upper panels, respectively) expressing the GFP-SpvC fusion protein.
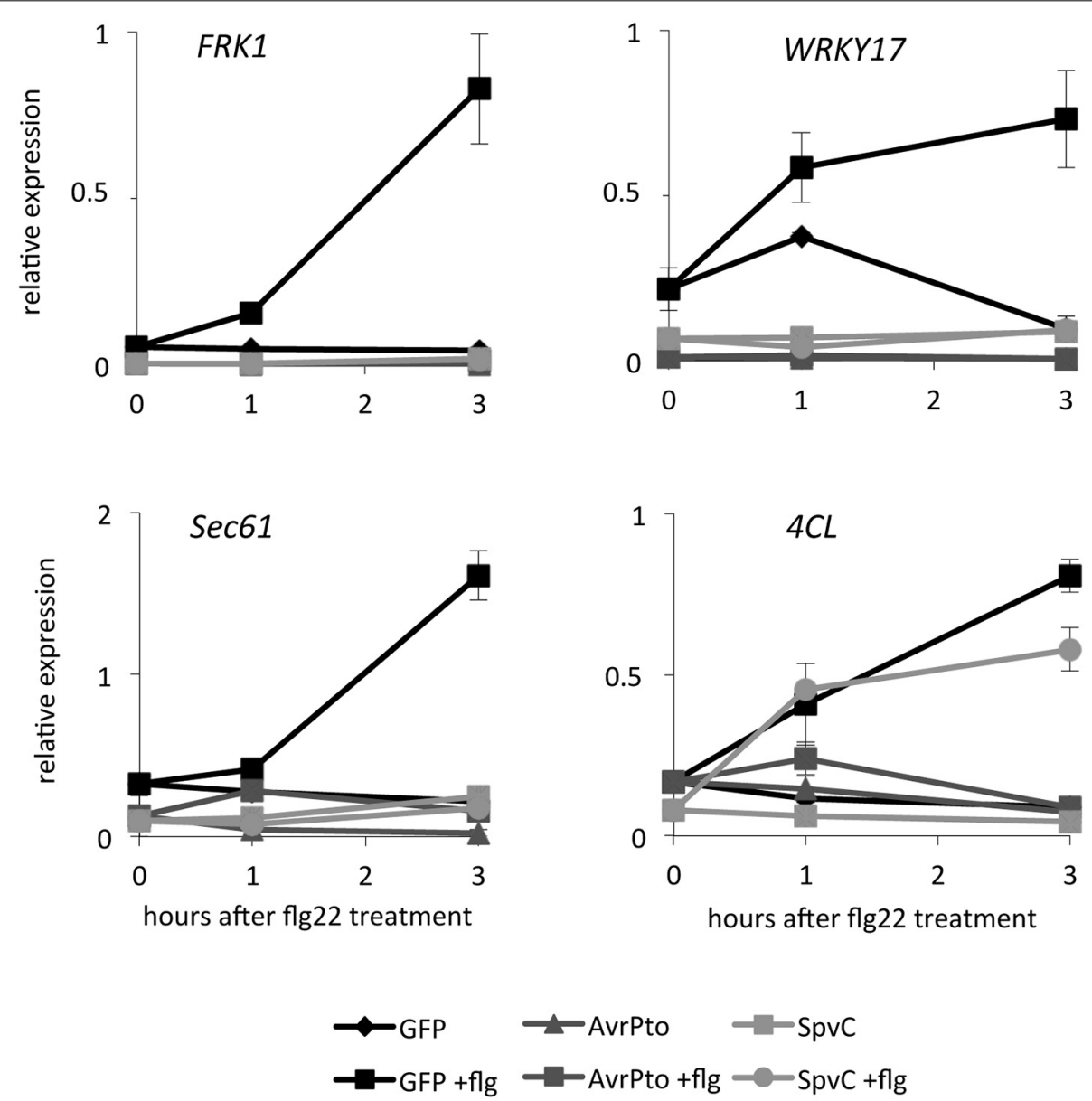

FIGURE 3 | SpvC attenuates flg22-induced defense responses in protoplasts. Arabidopsis mesophyll protoplasts were transformed with p2FGW7 (GFP), p2GW7-AvrPto (AvrPto) or p2GW7-SpvC (SpvC) plasmids and subsequently challenged with flg22. Samples were collected 1 and $3 \mathrm{~h}$ after treatment. Relative expression levels of FRK1, WRKY17, Sec61, and $4 C L$ were assessed using quantitative RT-PCR and normalized to the expression of the house-keeping gene actin. The graphs show one representative experiment out of three. Data is presented as mean values \pm s.e.m. of three technical replicates. Expression of FRK1, WRKY17, and Sec61 was attenuated in protoplasts in the presence of SpvC. However, SpvC had no impact on the expression of $4 C L$. as a GFP-tagged version (GFP-SpvC) and transformed leaves were inoculated with $\mathrm{Bgh}$ conidia. On control-transformed ( $m$ Cherry) cells about $48 \%$ of $B g h$ conidia germinated $24 \mathrm{~h}$ after inoculation, though all of the germinated conidia died or did not develop any further in the following $24 \mathrm{~h}$ (Figure 6A). In contrast, in cells expressing GFP-SpvC the percentage of germinated conidia increased to $66 \%$ and the later developed into secondary hyphae was observed in $11 \%$ of the transformed cells (Figure 6A). These results suggest that $B g h$ successfully penetrated into part of the epidermal cells that expressed GFP-SpvC. We conclude that the efficient defense mechanism against $B g h$ is at least partially compromised when SpvC is present in the cell, most likely due to its effect on MAPKs and the subsequent inhibition of PTI.

\section{SpvC IS REQUIRED FOR FULL VIRULENCE OF SALMONELLA TOWARD PLANTS}

The $\Delta s p v C$ mutant is characterized by attenuated virulence in the mouse model (Mazurkiewicz et al., 2008) and SpvC is thought to play a crucial role in systemic bacteremia in humans [reviewed in Guiney and Fierer, 2011]. To assess the question whether 


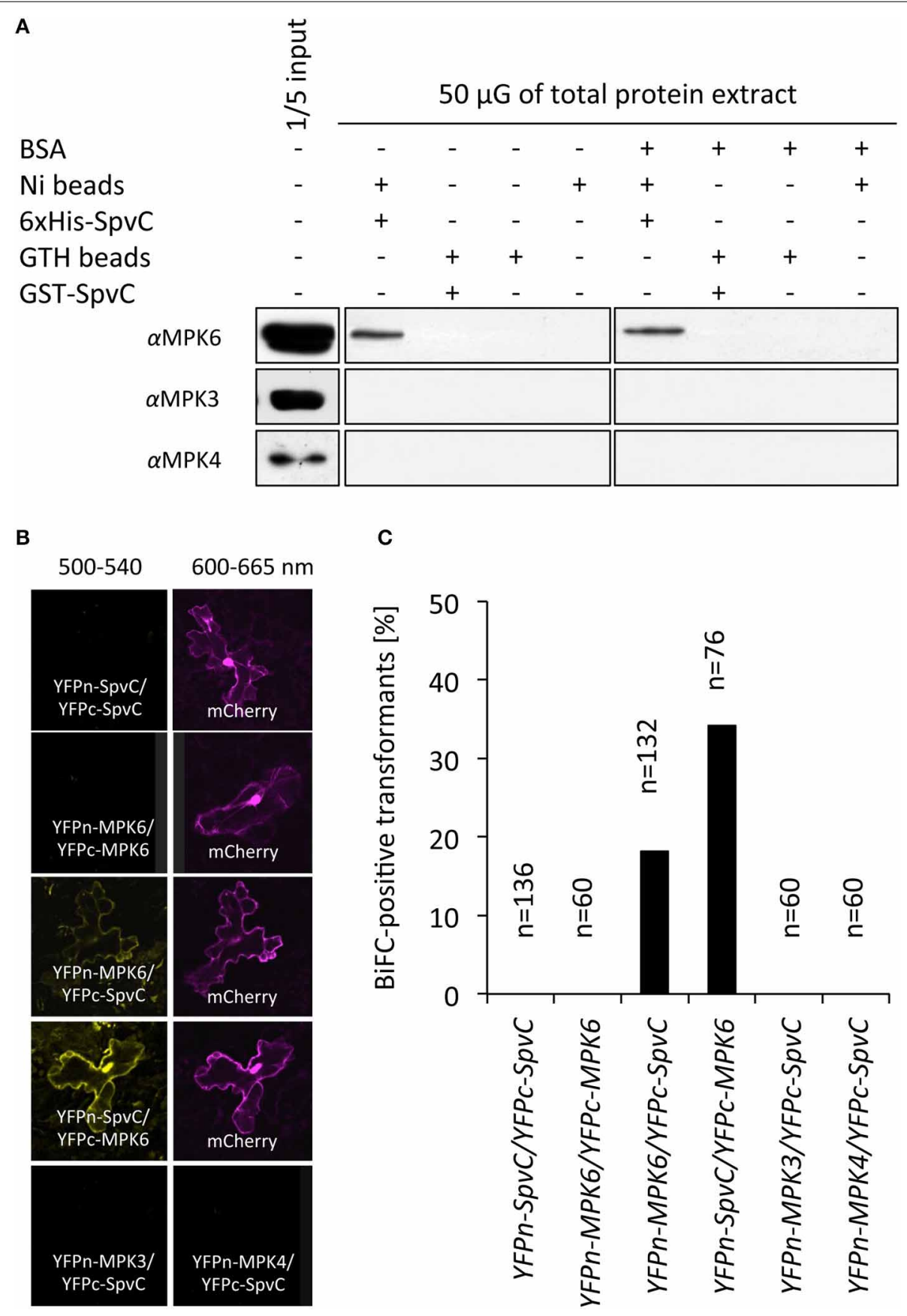

FIGURE 4 | Arabidopsis MPK6 interacts with the SpvC effector. (A) In a pull-down assay, recombinant 6 xHis-SpvC or GST-SpvC proteins were co-incubated with total protein extract from Arabidopsis seedlings and $\mathrm{Ni}$ - or GTH-coated beads, respectively, as indicated by "+". Anti-MPK6, anti-MPK3, and anti-MPK4-specific antibodies were used to visualize the presence of the respective kinases in $\mathrm{Ni}$ - or $\mathrm{GTH}$-binding complexes in an immunoblot analysis. Only MPK6 was detected, indicating a specific binding between MPK6 and 6xHis-SpvC, however not GST-SpvC, proteins. (B) Bimolecular fluorescence complementation (BiFC) assay was performed with full-length versions of MAPKs and SpvC cloned down-stream of a portion of the Yellow Fluorescent Protein (YFP) gene encoding the $\mathrm{N}$-terminal or C-terminal part of YFP in all four possible combinations. Arabidopsis epidermal cells were co-transformed with vectors carrying those constructs and vector carrying 35S-mCherry via particle bombardment. Fluorescence was observed $48 \mathrm{~h}$ after transformation. (C) Quantification of the interaction between SpvC and MAPKs as percentage of the transformed cells. mCherry-positive cells from four independent experiments were counted. The diagram represents the percentage of YFP-positive cells among transformed cells.
SpvC plays a significant role during proliferation in plants, we tested the performance of the $\Delta s p v C$ mutant on Arabidopsis plants. The $\Delta s p v C$ mutant was constructed by replacing the $S p v C$ gene with a chloramphenicol resistance cassette in the wild-type S. Typhimurium strain 14028s (Datsenko and Wanner, 2000). Six-week old, soil-grown Arabidopsis plants were syringeinfiltrated and the bacterial populations were monitored during 4 days. The wild-type $S$. Typhimurium 14028 s strain reached about 


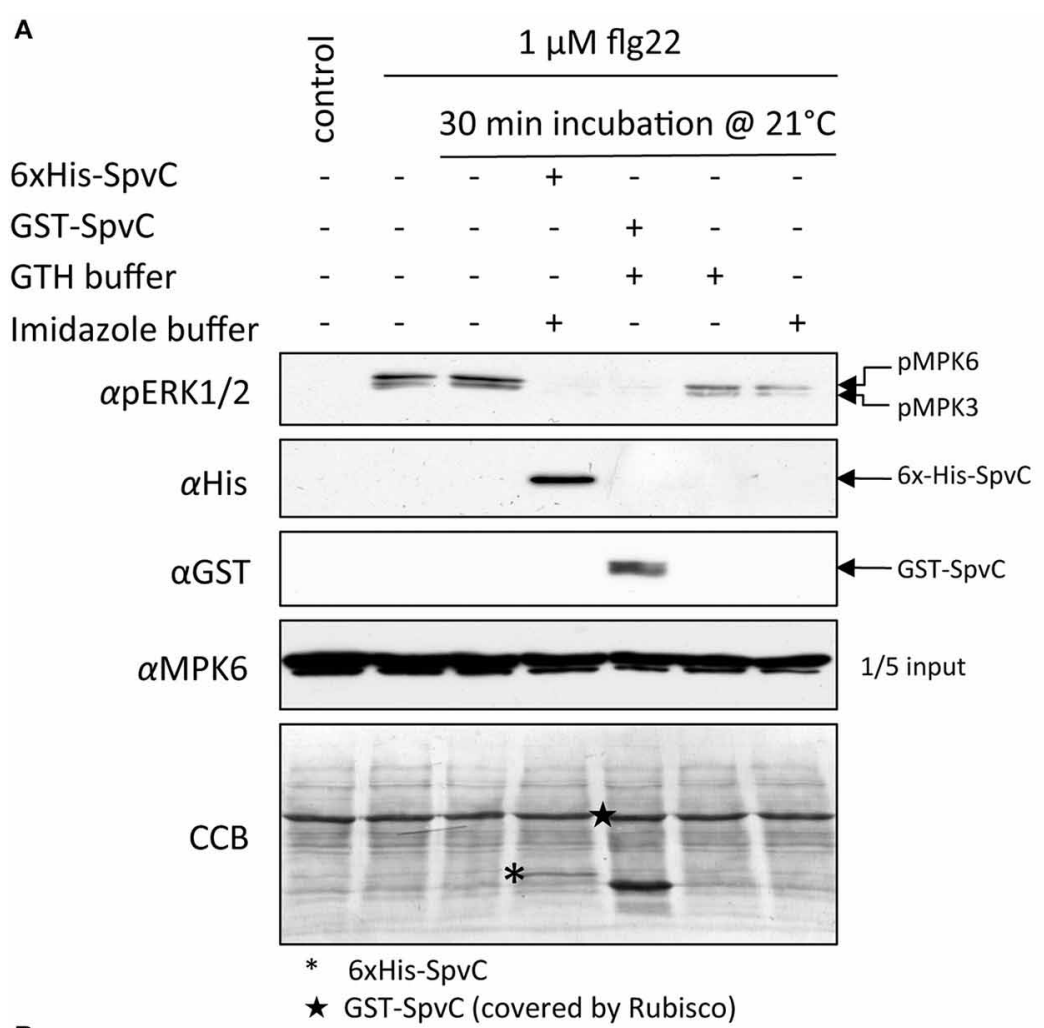

B

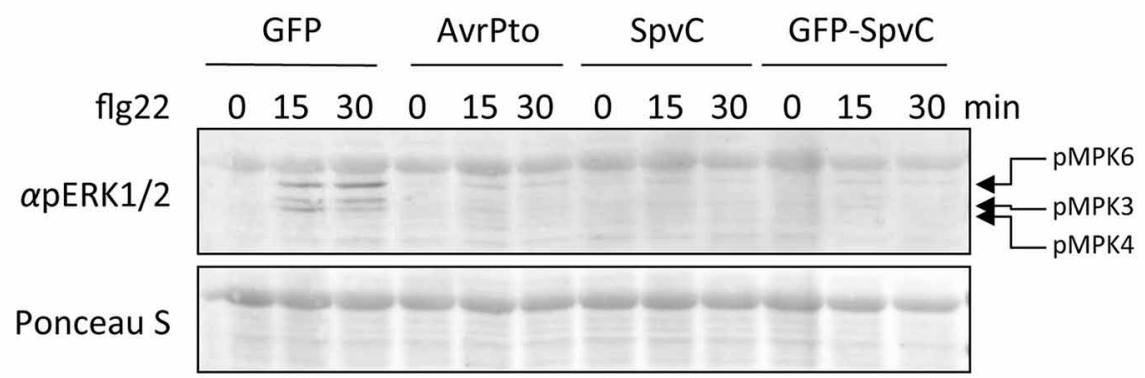

C

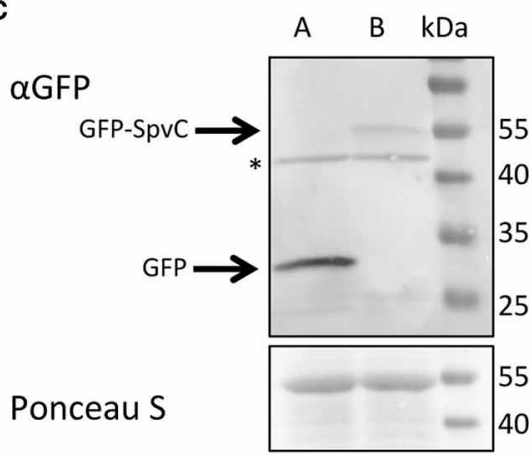

FIGURE 5 | Active MAPKs are dephosphorylated by SpvC. (A) MAPKs were activated by treatment of 2-week old seedlings with flg22 for 20 min prior to the extraction of total soluble proteins. Extracted proteins were then incubated for 30 min with purified recombinant $6 x$ His-SpvC or GST-SpvC proteins. The phosphorylation status of Arabidopsis MAPKs was analyzed by immunoblotting using an antibody raised against the phosphorylated form of EKR1/2 (apERK1/2). The recombinant proteins were probed with anti-His and anti-GST antibodies ( $\alpha$ His and $\alpha$ GST, respectively). Specific anti-MPK6

( $\alpha$ MPK6) antibody was used to assess the presence of MPK6. CCB stain was
A; GFP
B; GFP-SpvC
* non-specific band

used to monitor the equal sample loading. (B) Arabidopsis protoplasts were transformed with p2FGW7 (GFP), p2GW7-AvrPto (AvrPto) or p2GW7-SpvC (SpvC) and subsequently treated with flg22 for 0,15 or $30 \mathrm{~min}$. The phosphorylation status of MAPKs was assessed with the $\alpha$ ERRK1/2 antibody. Treatment with flg22 caused phosphorylation of MPK6 and MPK3 as visible by the appearing bands at 15 and 30 min after treatment. However, signals are missing in protoplasts expressing AvrPto or SpvC. (C) Expression and stability of GFP-SpvC fusion protein in Arabidopsis protoplasts. Ponceau S staining was used to show equal sample loading. 


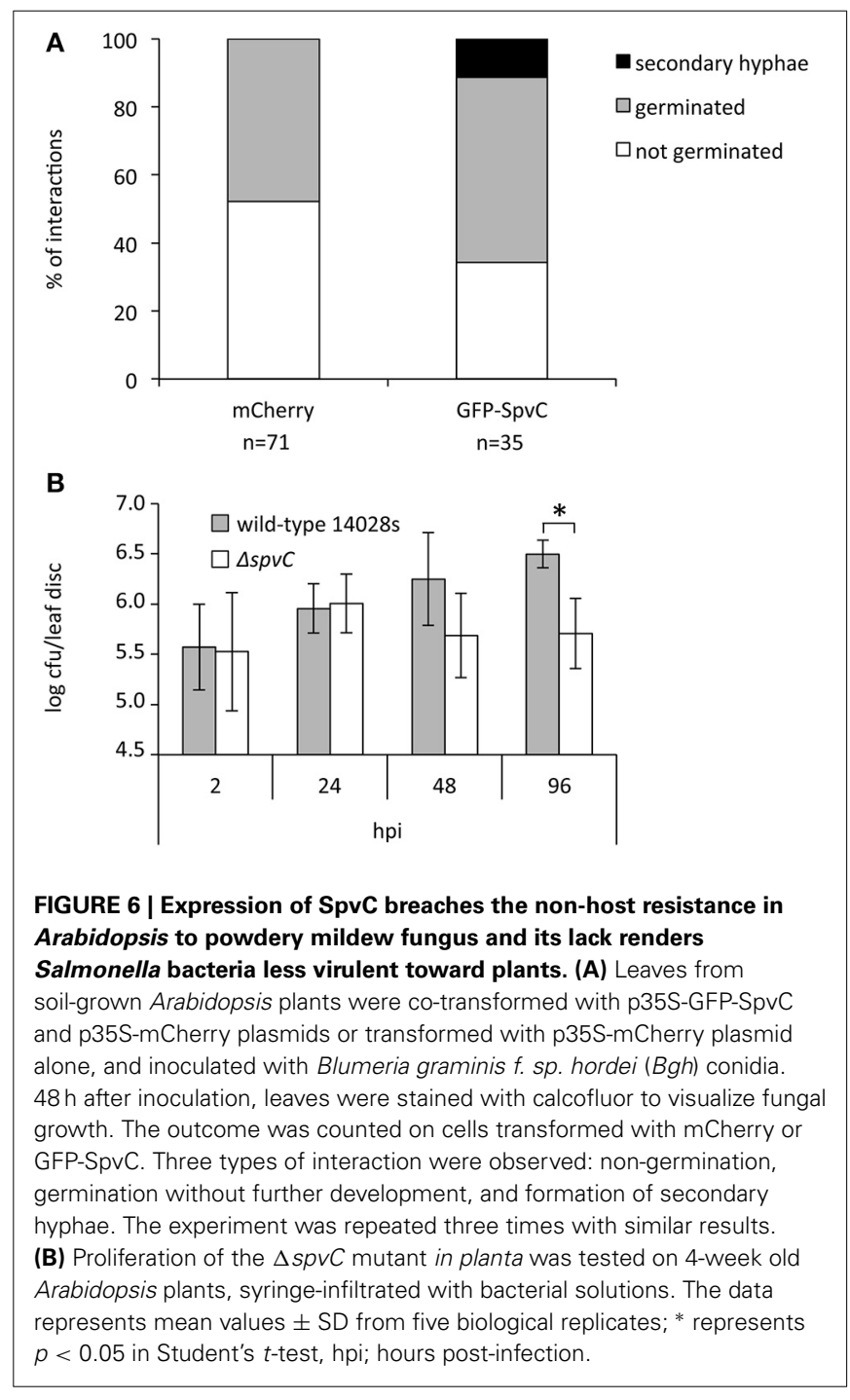

$10^{7}$ colony-forming units ( $\left.\mathrm{cfu}\right)$ in a leaf disc. In contrast to the wild-type, the $\Delta s p v C$ mutant showed a decreased ability to proliferate in Arabidopsis (Figure 6B), suggesting that SpvC plays a important role for Salmonella when present in a plant host.

\section{DISCUSSION}

In this report we performed a functional screen of Salmonella effector proteins and virulence factors in plants. We demonstrated that the function of the Salmonella effector protein SpvC is conserved in hosts originating from different kingdoms. In analogy to the infection in the animal system, SpvC interacts with plant MAPKs and dephosphorylates their active form, thus attenuating defense mechanisms. The presence of $S p v C$ in Arabidopsis cells repressed the induction of several defense-related genes and breached the non-host resistance toward B. graminis. Moreover, the mutant lacking $S p v C$ was less virulent on Arabidopsis plants when compared to the wild-type strain $S$. Typhimurium 14028s.

Among known Salmonella effectors, some are encoded on plasmids within a shared common locus called salmonella plasmid virulence (spv) (Boyd and Hartl, 1998). The spv operon is absolutely required for the development of a lethal systemic infection in the mouse model (Montenegro et al., 1991; Fierer et al., 1992; Gulig and Doyle, 1993). The expression of the $s p v$ operon (encoding five proteins: SpvR, A, B, C, and D) is strongly induced in intracellular bacteria and is regulated by the positive transcriptional regulator SpvR and the sigma factor RpoS (Fang et al., 1991; Krause et al., 1992). SpvC is a phosphothreonine lyase that dephosphorylates the double phosphorylated pTXpY activation loop in the kinases ERK1/2, as well as in p38 and probably JNK (Li et al., 2007; Mazurkiewicz et al., 2008; Haneda et al., 2012). In consequence, SpvC blocks the proinflammatory function of the MAPK pathway, facilitating the cell-to-cell spread of bacteria. In contrast to the dual-specificity phosphatases, which cleave the C-P bond, SpvC cleaves the C$\mathrm{O}$ bond, promoting the formation of $\beta$-methyldehydroalanine, which cannot be re-phosphorylated. The enzymatic activity of SpvC is common to the OspF family, named after the first characterized effector protein OspF from Shigella flexneri (Arbibe et al., 2007; Li et al., 2007; Smith et al., 2009). Interestingly, also plant pathogens possess members of the OspF family. HopAI1 from Pseudomonas syringe is a close homolog to OspF/SpvC, and has similarly to the Salmonella protein, a phosphothreonine lyase activity. Previously, HopAI1 has been shown to dephosphorylate activated MPK3 and MPK6 in Arabidopsis plants (Zhang et al., 2007). Recently, MPK4 was also shown to be targeted and dephosphorylated by HopAI1 (Zhang et al., 2012).

Here, we demonstrate that SpvC dephosphorylates three activated MAPKs (MPK3, MPK4, and MPK6) in Arabidopsis. In both performed tests, the presence of SpvC caused loss of the phosphorylated pTEpY epitope on the MAPKs. On the one hand, the assumption that the biochemical action (cleavage of $\mathrm{C}-\mathrm{O}$ bond) of SpvC on active plant MAPKs is similar to its action on $\mathrm{pERK} 1 / 2$ is very tempting, remains however to be verified. On the other hand, the dephosphorylation of MAPK3/4/6 by $\mathrm{SpvC}$ is clearly coupled to the attenuation of the plant defense responses. When present in Arabidopsis protoplasts, SpvC hinders the expression of several defense-associated genes. It also lowers the resistance of Arabidopsis cells against the biotrophic, non-host pathogen $B g h$, a phenomenon observed in defensecompromised mutants [reviewed in Lipka et al., 2008)]. Similarly to the situation in animal cells, where SpvC blocks the proinflammatory pathway and therefore the actual defense response, inhibition of MAPKs in plants seems to block the otherwise efficient defense strategy. How specific the particular MAPKs are targeted by SpvC could not be answered. The dephosphorylation assays clearly showed the possibility to dephosphorylate MPK3, MPK4, and MPK6, a situation similar to HopAI1 (Zhang et al., 2012). Nevertheless, in contrast to MPK6, interaction of SpvC with MPK3 or MPK4 could be verified neither in BiFC nor in pull-down assays, which indicates a high affinity of SpvC toward MPK6 or that interaction with MPK3 or MPK4 requires yet other components.

During animal infection, SpvC induces late macrophage apoptosis. However, no cell death-inducing activity could be detected in plants. In contrast to macrophage apoptosis used by Salmonella 
to facilitate the cell-to-cell spread in animal organism, cellular death in plants (hypersensitive response; HR) is very often a defense mechanism induced by recognition of pathogen effector proteins by the plant intracellular $\mathrm{R}$ proteins. Despite the fact that SpvC is a T3SS-translocated effector in mammalian cells, the described above screen in tobacco leaves suggests that SpvC does not induce the hallmark of effector-triggered immunity (ETI) in plants, the HR, implying that SpvC is not recognized by $\mathrm{R}$ protein(s). We also exclude the possibility that SpvC is recognized by surface located receptors by testing its PAMP activity. Growth inhibition and production of reactive oxygen species, both hallmarks of pattern-triggered immunity (PTI), were studied in plants after contact with SpvC (Supplementary Figure S2). Our results suggest that $\mathrm{SpvC}$ is not toxic for plant cells when externally present and that plants do not recognize SpvC by potential surface receptor(s).

As described above, the intracellular presence of SpvC attenuated the activation of MPK3/4/6 and expression of several defense-related genes. Whether, besides inhibition of those two aspects of plant defense, SpvC actively suppresses the HR response remains to be verified in future experiments. Furthermore, the translocation of Salmonella effector proteins into plant cytoplasm was not yet demonstrated. The function of $\mathrm{SpvC}$ requires its presence in the host cytoplasm, therefore a direct evidence of translocation of this effector (or/and others) needs to be provided in future work, as this would certainly help to understand how these bacteria suppress plant immune responses. Interesting was the observation that expression of other Salmonella effectors in planta induced visible changes. SseF and SseG, both SPI-2 encoded effector proteins involved in the trafficking of Salmonella Containing Vacuole (SCV) in animal cells, induced HR-like (SseF) or yellowing (SseG) symptoms in tobacco leaves, when expressed via Agrobacterium-mediated transformation. It confirms the observation made by Ustun et al. (2012), who showed that SseF from $S$. enterica triggers HR-like symptoms in tobacco plants when expressed transiently via Agrobacterium infiltration or delivered via the T3SS from Xanthomonas campestris $p v$. vesicatoria. Moreover, the ability of SseF to trigger HR-like symptoms was lost upon silencing of SGT1 (suppressor of G2 allele of skp1), which is required for HR induction in tobacco. These results indicate that Salmonella SseF is recognized in N. benthamiana via an $\mathrm{R}$ protein-mediated mechanism and triggers ETI in consequence. Surprisingly, expression of $S p t P$ or $\operatorname{Slr} P$, both postulated to be key effectors of Salmonella with the highest number of predicted protein-protein interactions (Schleker et al., 2012), induced no visible symptoms in tobacco leaves nor had an effect on the induction of pFRK1-Luc in Arabidopsis protoplasts.

In summary, an increasing number of evidence indicates that plants evolved diverse mechanisms to recognize Salmonella bacteria using surface receptors as well as intracellular R proteins. Our study supports the view that Salmonella also evolved means to interfere with plant immunity by efficiently employing its repertoire of effector proteins to succumb plant immune responses. Consequently, Salmonella, and possibly other human pathogenic bacteria, seems to possess effective tools for suppression of the plant immune system.

\section{ACKNOWLEDGMENTS}

The work of Casandra Hernàndez-Reyes was supported by CONACYT fellowship from the Mexican Ministry for Science. Heribert Hirt was supported by a grant of the ERANET Systems Biology project SHIPREC (Salmonella Host Interaction Project European Consortium).

\section{SUPPLEMENTARY MATERIAL}

The Supplementary Material for this article can be found online at: http://www.frontiersin.org/journal/10.3389/fmicb. 2014.00548/abstract

\section{REFERENCES}

Arbibe, L., Kim, D. W., Batsche, E., Pedron, T., Mateescu, B., Muchardt, C., et al. (2007). An injected bacterial effector targets chromatin access for transcription factor NF-kappaB to alter transcription of host genes involved in immune responses. Nat. Immunol. 8, 47-56. doi: 10.1038/ni1423

Asai, T., Tena, G., Plotnikova, J., Willmann, M. R., Chiu, W. L., Gomez-Gomez, L., et al. (2002). MAP kinase signalling cascade in Arabidopsis innate immunity. Nature 415, 977-983. doi: 10.1038/415977a

Bethke, G., Unthan, T., Uhrig, J. F., Poschl, Y., Gust, A. A., Scheel, D., et al. (2009). Flg22 regulates the release of an ethylene response factor substrate from MAP kinase 6 in Arabidopsis thaliana via ethylene signaling. Proc. Natl. Acad. Sci. USA. 106, 8067-8072. doi: 10.1073/pnas.0810206106

Boller, T. (2012). Experimental evidence of a role for RLKs in innate immunity. Signal. Commun. Plants 13, 67-77. doi: 10.1007/978-3-642-23044-8_4

Boyd, E. F., and Hartl, D. L. (1998). Salmonella virulence plasmid. Modular acquisition of the spv virulence region by an F-plasmid in Salmonella enterica subspecies I and insertion into the chromosome of subspecies II, IIIa, IV and VII isolates. Genetics 149, 1183-1190.

Chu, C., and Chiu, C. H. (2006). Evolution of the virulence plasmids of nontyphoid Salmonella and its association with antimicrobial resistance. Microbes Infect. 8, 1931-1936. doi: 10.1016/j.micinf.2005.12.026

Datsenko, K. A., and Wanner, B. L. (2000). One-step inactivation of chromosomal genes in Escherichia coli K-12 using PCR products. Proc. Natl. Acad. Sci. U.S.A. 97, 6640-6645. doi: 10.1073/pnas.120163297

Fang, F. C., Krause, M., Roudier, C., Fierer, J., and Guiney, D. G. (1991). Growth regulation of a Salmonella plasmid gene essential for virulence. J. Bacteriol. 173, 6783-6789.

Felix, G., Duran, J. D., Volko, S., and Boller, T. (1999). Plants have a sensitive perception system for the most conserved domain of bacterial flagellin. Plant J. 18, 265-276. doi: 10.1046/j.1365-313X.1999.00265.x

Fierer, J., Krause, M., Tauxe, R., and Guiney, D. (1992). Salmonella typhimurium bacteremia: association with the virulence plasmid. J. Infect. Dis. 166, 639-642. doi: 10.1093/infdis/166.3.639

Fraiture, M., Zheng, X., and Brunner, F. (2014). An Arabidopsis and tomato mesophyll protoplast system for fast identification of early MAMP-triggered immunity-suppressing effectors. Methods Mol. Biol. 1127, 213-230. doi: 10.1007/978-1-62703-986-4_17

Garcia, A. V., Charrier, A., Schikora, A., Bigeard, J., Pateyron, S., De Tauzia-Moreau, M. L., et al. (2014). Salmonella enterica flagellin is recognized via FLS2 and activates PAMP-triggered immunity in Arabidopsis thaliana. Mol. Plant 7, 657-674. doi: $10.1093 / \mathrm{mp} / \mathrm{sst} 145$

Golberg, D., Kroupitski, Y., Belausov, E., Pinto, R., and Sela, S. (2011). Salmonella typhimurium internalization is variable in leafy vegetables and fresh herbs. Int. J. Food Microbiol. 145, 250-257. doi: 10.1016/j.ijfoodmicro. 2010.12.031

Guiney, D. G., and Fierer, J. (2011). The role of the spv genes in Salmonella pathogenesis. Front. Microbiol. 2:129. doi: 10.3389/fmicb.2011.00129

Gulig, P. A., and Doyle, T. J. (1993). The Salmonella typhimurium virulence plasmid increases the growth rate of salmonellae in mice. Infect. Immun. 61, 504-511.

Haapalainen, M., Van Gestel, K., Pirhonen, M., and Taira, S. (2009). Soluble plant cell signals induce the expression of the type III secretion system of Pseudomonas syringae and upregulate the production of pilus protein HrpA. Mol. Plant Microbe Interact. 22, 282-290. doi: 10.1094/MPMI-22-3-0282 
Hamel, L. P., Miles, G. P., Samuel, M. A., Ellis, B. E., Seguin, A., and Beaudoin, N. (2005). Activation of stress-responsive mitogen-activated protein kinase pathways in hybrid poplar (Populus trichocarpa x Populus deltoides). Tree Physiol. 25, 277-288. doi: 10.1093/treephys/25.3.277

Haneda, T., Ishii, Y., Shimizu, H., Ohshima, K., Iida, N., Danbara, H., et al. (2012). Salmonella type III effector SpvC, a phosphothreonine lyase, contributes to reduction in inflammatory response during intestinal phase of infection. Cell. Microbiol. 14, 485-499. doi: 10.1111/j.1462-5822.2011.01733.x

He, P., Shan, L., Lin, N. C., Martin, G. B., Kemmerling, B., Nurnberger, T., et al. (2006). Specific bacterial suppressors of MAMP signaling upstream of MAPKKK in Arabidopsis innate immunity. Cell 125, 563-575. doi: 10.1016/j.cell.2006.02.047

Heffron, F., Niemann, G., Yoon, H., Kidwai, A., Brown, R., McDemrott, J., et al. (2011). "Salmonella-secreted virulence factors," in Salmonella from Genom to Function, ed S. Porwollik (San Diego, CA: Caister Academic Press), 187-223.

Holden, N., Pritchard, L., and Toth, I. (2009). Colonization outwith the colon: plants as an alternative environmental reservoir for human pathogenic enterobacteria. FEMS Microbiol. Rev. 33, 689-703. doi: 10.1111/j.15746976.2008.00153.x

Jones, J. D., and Dangl, J. L. (2006). The plant immune system. Nature 444, 323-329. doi: 10.1038/nature05286

Krause, M., Fang, F. C., and Guiney, D. G. (1992). Regulation of plasmid virulence gene expression in Salmonella dublin involves an unusual operon structure. J. Bacteriol. 174, 4482-4489.

Kroupitski, Y., Golberg, D., Belausov, E., Pinto, R., Swartzberg, D., Granot, D., et al. (2009). Internalization of Salmonella enterica in leaves is induced by light and involves chemotaxis and penetration through open stomata. Appl. Environ. Microbiol. 75, 6076-6086. doi: 10.1128/AEM.01084-09

Li, H., Xu, H., Zhou, Y., Zhang, J., Long, C., Li, S., et al. (2007). The phosphothreonine lyase activity of a bacterial type III effector family. Science 315, 1000-1003. doi: 10.1126/science. 1138960

Lipka, U., Fuchs, R., and Lipka, V. (2008). Arabidopsis non-host resistance to powdery mildews. Curr. Opin. Plant Biol. 11, 404-411. doi: 10.1016/j.pbi.2008.04.004

Mazurkiewicz, P., Thomas, J., Thompson, J. A., Liu, M., Arbibe, L., Sansonetti, P., et al. (2008). SpvC is a Salmonella effector with phosphothreonine lyase activity on host mitogen-activated protein kinases. Mol. Microbiol. 67, 1371-1383. doi: 10.1111/j.1365-2958.2008.06134.x

Meng, F., Altier, C., and Martin, G. B. (2013). Salmonella colonization activates the plant immune system and benefits from association with plant pathogenic bacteria. Environ. Microbiol. 15, 2418-2430. doi: 10.1111/1462-2920.12113

Milillo, S. R., Badamo, J. M., Boor, K. J., and Wiedmann, M. (2008). Growth and persistence of Listeria monocytogenes isolates on the plant model Arabidopsis thaliana. Food Microbiol. 25, 698-704. doi: 10.1016/j.fm.2008.03.003

Montenegro, M. A., Morelli, G., and Helmuth, R. (1991). Heteroduplex analysis of Salmonella virulence plasmids and their prevalence in isolates of defined sources. Microb. Pathog. 11, 391-397. doi: 10.1016/0882-4010(91)90035-9

Pang, T., Bhutta, Z. A., Finlay, B. B., and Altwegg, M. (1995). Typhoid fever and other salmonellosis: a continuing challenge. Trends Microbiol. 3, 253-255. doi: 10.1016/S0966-842X(00)88937-4

Pitzschke, A., Schikora, A., and Hirt, H. (2009). MAPK cascade signalling networks in plant defence. Curr. Opin. Plant Biol. 12, 421-426. doi: 10.1016/j.pbi.2009.06.008

Prithiviraj, B., Bais, H. P., Jha, A. K., and Vivanco, J. M. (2005). Staphylococcus aureus pathogenicity on Arabidopsis thaliana is mediated either by a direct effect of salicylic acid on the pathogen or by SA-dependent, NPR1-independent host responses. Plant J. 42, 417-432. doi: 10.1111/j.1365-313X.2005.02385.x

Rangel, J. M., Sparling, P. H., Crowe, C., Griffin, P. M., and Swerdlow, D. L. (2005). Epidemiology of Escherichia coli O157:H7 outbreaks, United States, 1982-2002. Emerg. Infect. Dis. 11, 603-609. doi: 10.3201/eid1104.040739
Schikora, A., Carreri, A., Charpentier, E., and Hirt, H. (2008). The dark side of the salad: Salmonella typhimurium overcomes the innate immune response of Arabidopsis thaliana and shows an endopathogenic lifestyle. PLoS ONE 3:e2279. doi: 10.1371/journal.pone.0002279

Schikora, A., Virlogeux-Payant, I., Bueso, E., Garcia, A. V., Nilau, T., Charrier, A., et al. (2011). Conservation of Salmonella infection mechanisms in plants and animals. PLoS ONE 6:e24112. doi: 10.1371/journal.pone.0024112

Schleker, S., Garcia-Garcia, J., Klein-Seetharaman, J., and Oliva, B. (2012). Prediction and comparison of salmonellahuman and salmonellaarabidopsis interactomes. Chem. Biodivers. 9, 991-1018. doi: 10.1002/cbdv.201 100392

Shirron, N., and Yaron, S. (2011). Active suppression of early immune response in tobacco by the human pathogen Salmonella typhimurium. PLoS ONE 6:e18855. doi: 10.1371/journal.pone.0018855

Smith, G. K., Ke, Z., Hengge, A. C., Xu, D., Xie, D., and Guo, H. (2009). Active-site dynamics of SpvC virulence factor from Salmonella typhimurium and density functional theory study of phosphothreonine lyase catalysis. J. Phys. Chem. B 113, 15327-15333. doi: 10.1021/jp9052677

Ustun, S., Muller, P., Palmisano, R., Hensel, M., and Bornke, F. (2012). SseF, a type III effector protein from the mammalian pathogen Salmonella enterica, requires resistance-gene-mediated signalling to activate cell death in the model plant Nicotiana benthamiana. New Phytol. 194, 1046-1060. doi: 10.1111/j.14698137.2012.04124.x

Westrell, T., Ciampa, N., Boelaert, F., Helwigh, B., Korsgaard, H., Chriel, M., et al. (2009). Zoonotic infections in Europe in 2007: a summary of the EFSA-ECDC annual report. Euro Surveill. 14. Available online at: http://www. eurosurveillance.org/ViewArticle.aspx?ArticleId=19100

Yoo, S. D., Cho, Y. H., and Sheen, J. (2007). Arabidopsis mesophyll protoplasts: a versatile cell system for transient gene expression analysis. Nat. Protoc. 2, 1565-1572. doi: 10.1038/nprot.2007.199

Zhang, J., Shao, F., Li, Y., Cui, H., Chen, L., Li, H., et al. (2007). A Pseudomonas syringae effector inactivates MAPKs to suppress PAMP-induced immunity in plants. Cell Host Microbe 1, 175-185. doi: 10.1016/j.chom.2007.03.006

Zhang, Z., Wu, Y., Gao, M., Zhang, J., Kong, Q., Liu, Y., et al. (2012). Disruption of PAMP-induced MAP kinase cascade by a Pseudomonas syringae effector activates plant immunity mediated by the NB-LRR protein SUMM2. Cell Host Microbe 11, 253-263. doi: 10.1016/j.chom.2012.01.015

Zheng, X., McLellan, H., Fraiture, M., Liu, X., Boevink, P. C., Gilroy, E. M., et al. (2014). Functionally redundant RXLR effectors from Phytophthora infestans act at different steps to suppress early flg22-triggered immunity. PLoS Pathog. 10:e1004057. doi: 10.1371/journal.ppat.1004057

Conflict of Interest Statement: The authors declare that the research was conducted in the absence of any commercial or financial relationships that could be construed as a potential conflict of interest.

Received: 29 April 2014; accepted: 01 October 2014; published online: 17 October 2014. Citation: Neumann C, Fraiture M, Hernàndez-Reyes C, Akum FN, Virlogeux-Payant I, Chen Y, Pateyron S, Colcombet J, Kogel K-H, Hirt H, Brunner F and Schikora A (2014) The Salmonella effector protein SpvC, a phosphothreonine lyase is functional in plant cells. Front. Microbiol. 5:548. doi: 10.3389/fmicb.2014.00548

This article was submitted to Plant-Microbe Interaction, a section of the journal Frontiers in Microbiology.

Copyright (c) 2014 Neumann, Fraiture, Hernàndez-Reyes, Akum, Virlogeux-Payant, Chen, Pateyron, Colcombet, Kogel, Hirt, Brunner and Schikora. This is an openaccess article distributed under the terms of the Creative Commons Attribution License (CC BY). The use, distribution or reproduction in other forums is permitted, provided the original author(s) or licensor are credited and that the original publication in this journal is cited, in accordance with accepted academic practice. No use, distribution or reproduction is permitted which does not comply with these terms. 